\title{
Olfactory dysfunction in patients with chronic rhinosinusitis with nasal polyps is associated with clinical-cytological grading severity
}

\author{
La disfunzione olfattoria è associata con la gravità del grading clinico-citologico \\ nei pazienti con rinosinusite cronica con poliposi nasale
}

\author{
M. GELARDI ${ }^{1}$, K. PICCININNII', N. QUARANTA ${ }^{1}$, V. QUARANTA², M. SILVESTRI ${ }^{3}$, G. CIPRANDI ${ }^{4}$ \\ ${ }^{1}$ Otolaryngology, Department of Basic Medical Science, Neuroscience and Sensory Organs, University of Bari \\ "Aldo Moro", Bari, Italy; ${ }^{2}$ Pulmonology Unit, Ospedale Di Venere, Bari, Italy; ${ }^{3}$ Pediatric Pulmonology, IRCCS Istituto \\ Giannina Gaslini, Genoa, Italy; ${ }^{4}$ Allergy Clinic, Casa di Cura Villa Montallegro, Genoa, Italy
}

\section{SUMMARY}

Chronic rhinosinusitis with nasal polyps (CRSwNP) is a common inflammatory disorder, affecting about $4 \%$ of the worldwide population and strongly impacting the quality of life. CRSwNP is still a challenge for ENT specialists in terms of its unknown pathogenesis, difficulty in management and frequent relapse. Olfactory impairment frequently affects CRSwNP patients. We tested the hypothesis that clinicalcytological grading (CCG) could be associated with olfactory dysfunction. The study was cross-sectional, enrolling 62 patients (37 males, 25 females, mean age 49 years, range 18-83) suffering from newly diagnosed CRSwNP. Olfactory dysfunction was very frequent (about $90 \%$ ) and did not depend on nasal obstruction as assessed by both polyp size and nasal airflow limitation. A CCG $>4$ was the best cutoff value to suspect olfactory dysfunction [area under the ROC curve of 0.831 ( 0.715 to 0.914 )]; in addition, the statistical risk of having dysosmia was over 7-fold higher in subjects with CCG > 4 compared with subjects reporting a CCG $<4$ (adjOR 7.46). The present study underlines that olfactory dysfunction is common in CRSwNP patients and demonstrates an association between olfactory dysfunction and inflammation, suggesting that CCG could be useful in the work-up of CRSwNP patients and in suspecting olfactory impairment.

KEY WORDS: Chronic rhinosinusitis with nasal polyps $\bullet$ Clinical grading $\bullet$ Cytological grading $\bullet$ Olfactory dysfunction

\section{RIASSUNTO}

La rinosinusite cronica con poliposi nasale (RSCPN) è una malattia infiammatoria abbastanza frequente, in quanto ne è affetto circa il $4 \%$ della popolazione generale ed ha un notevole impatto sulla qualità della vita dei pazienti. Peraltro la RSCPN rappresenta un problema per lo specialista ORL per quanto riguarda la patogenesi, il difficile controllo e le frequenti recidive. Un difetto olfattorio è comune nei pazienti con RSCPN. Lo scopo dello studio trasversale era la valutazione dell'algoritmo basato sul grading clinico-citologico (GCC) in funzione del disturbo olfattivo in un campione di 62 pazienti (37 maschi, 25 femmine, età media 49 anni, con intervallo di età tra 18 ed 83 anni) con nuova diagnosi di RSCPN. Il difetto olfattivo era molto frequente (circa nel $90 \%$ dei casi) e non dipendeva dall'ostruzione nasale ma dall'infiammazione. Un valore di GCC > 4 potrebbe essere una soglia in grado di indurre il sospetto di un'alterazione dell'olfatto (area sotto la curva 0,83, ORadj 7,46). In conclusione, questo studio sottolinea la frequente presenza di un'alterazione dell'olfatto nei pazienti con RSCCPN e dimostra che i disturbi dell'olfatto sono associati con i fenomeni infiammatori e la valutazione del GCC potrebbe essere utile nel sospettare un'alterazione dell'olfatto.

PAROLE CHIAVE: Rinosinusite cronica con poliposi nasale $\bullet$ Grading clinic $\bullet$ Grading citologico $\bullet$ Disturbi dell'olfatto

\section{Introduction}

Chronic rhinosinusitis with nasal polyps (CRSwNP) is characterised by an inflammatory process involving the nasal mucosa. CRSwNP affects about $4 \%$ of the worldwide population and may strongly impair the quality of life ${ }^{1}$. CRSwNP represents an intriguing challenge for ENT specialists in terms of its unknown pathogenesis, difficulty in management and frequent relapse.
CRSwNP may be classified according to: comorbidity ${ }^{2}$, endoscopic outcomes ${ }^{3}$, X-ray features ${ }^{4}$, and cytological pattern ${ }^{5}$. In particular, a clinical-cytological grading (CCG) has been proposed to better define the management strategy, individuate a prognostic index of relapse ${ }^{6}$ and adopt a personalised medical approach ${ }^{7}$.

Olfactory defects are common in the general population with a prevalence ranging between $9.5 \%$ and $15.3 \%$, 
which is higher in elderly subjects and males ${ }^{8}$. Olfactory defects may be classified as hyposmia (partial defect of smell) and anosmia (total loss of smell). Rhinosinusitis is a common cause of chronic olfactory impairment in patients with nasal disorders ${ }^{9}$. Indeed, patients with CRSwNP frequently suffer from olfactory defects ${ }^{10}$. A longitudinal study demonstrated that nasal eosinophilia is a negative predictive factor for olfactory recovery after surgery ${ }^{11}$. Moreover, it has been reported that improved olfaction significantly enhanced quality of life score ${ }^{12}$.

Olfactory exploration is fundamental in patients with CRSwNP ${ }^{13}$. Olfactory assessment is based on history, clinical examination (mainly by fibreoptic endoscopy) and smell testing (e.g. psychophysical test Sniffin'Sticks). The "Sniffin'Sticks" olfactometric test has been validated and used in many studies ${ }^{14}$. The "Sniffin'Sticks" is a test of nasal chemosensory performance based on pen-like odour from a dispensing device ${ }^{15}$. The test evaluates three olfactory functions: odour threshold, odour discrimination and odour identification ${ }^{16-18}$.

On the basis of this background, the present study evaluated which factors, including CCG, are associated with olfactory defects in patients with newly diagnosed CRSwNP.

\section{Materials and methods}

\section{Study population}

Sixty-two patients (37 males, 25 females, mean age 49 years, range $18-83$ years) were consecutively visited at the Rhinology Unit of the ENT Clinic of the Bari University (Italy) and were enrolled in this cross-sectional study from June 2017 to June 2018.

The inclusion criteria were: 1) age $>18$ years of age; 2) male or female; 3 ) suffering from newly diagnosed CRSwNP; 4) informed written consent.

The exclusion criteria were: 1) current or past treatment for NP; 2) previous functional endoscopic sinus surgery (FESS); 3) past surgery for NP, CRS and septal deviation; 4) severe anatomic defects; 5) secondary olfactory defects; 6) NP limited to the olfactory fissure; 7) severe anatomic defect of the nasal cavity and/or nasal pyramid; 8 ) workers at chemical industries or exposed to volatile toxic substances; 9) past head trauma or brain injury, recent severe hyperthermia, or neurodegenerative disorders documented by neurological examination.

The Review Board approved the procedures used in this study.

\section{Study design}

All patients were evaluated by: clinical history, objective examination, fibreoptic endoscopy, nasal cytology, skin prick test, rhinomanometry, pulmonology visit and olfactometric test.

A diagnosis of CRSwNP was made according to validated criteria according to European and International guidelines ${ }^{119}$.

\section{Outcome}

The outcome of the current study was dysosmia as defined and scored below.

\section{Variables}

Nasal endoscopy was carried out by a $3.4 \mathrm{~mm}$ diameter flexible fibrescope (Vision-Sciences ${ }^{\circledR}$ ENT-2000). Nasal polyp endoscopic 4-grade classification proposed by Meltzer was adopted ${ }^{3}$.

Nasal cytology includes: sampling, processing and microscope reading. Sampling requires the collection of cells from the surface of middle portion of the inferior turbinate using a sterile disposable curette. The procedure is performed under anterior rhinoscopy, with an appropriate light source, and is completely painless. The sample obtained is immediately smeared on a glass slide, air-dried and stained with May-Grünwald-Giemsa (MGG) for 30 min. The stained sample was examined by optical microscopy with a 1000x objective with oil immersion. Fifty fields are considered the minimum number to identify a sufficient number of cells. The count of each cell type was expressed by a semi-quantitative grading as previously described ${ }^{20}$.

Skin prick test was performed as stated by the European Academy of Allergy and Clinical Immunology ${ }^{21}$. The allergen panel consisted of the following: house-dust mites (Dermatophagoidesfarinae and Dermatophagoidespteronyssinus), cats, dogs, grasses mix, Compositae mix, P. judaica, birch, hazel trees, olive trees, cypress, Alternaria tenuis, Cladosporium and Aspergilli mix. The concentration of allergen extracts was 100 immune reactivity $/ \mathrm{mL}$ (Stallergenes-Greer Italia, Milan, Italy). A histamine solution in distilled water $(10 \mathrm{mg} / \mathrm{mL})$ was used as a positive control and the glycerol-buffer diluent of allergen preparations was used as a negative control. Each patient was skin tested on the volar surface of the forearm using 1-mm prick lancets. The skin reaction was recorded after $15 \mathrm{~min}$ by evaluating the skin response in comparison with the wheal given by the positive and the negative control. A wheal diameter of at least $3 \mathrm{~mm}$ was considered as a positive reaction.

Rhinomanometry measured nasal airflow resistance by active anterior electronic rhinomanometry. Patients wore a tight-fitting facemask and breathed through one nostril 
with their mouth closed. A sensor, placed in the contralateral nostril, recorded data on pre- and postnasal pressures via airflow and pressure transducers. The instrument (Rhinomanometer Menfis, Amplifon, Italy) was connected to a personal computer. The signals of trans-nasal airflow and pressure were amplified, digitalised and saved for statistical analysis. Nasal resistance was measured in $\mathrm{ml} / \mathrm{sec}$ as the sum of the recorded airflow through the right and left nostrils at a pressure difference of $150 \mathrm{~Pa}$ across the nasal passage. Four or more airflow measurements were performed for each patient, and the mean value was recorded when reproducible values were achieved. Normal values are $0.50 \mathrm{~Pa} / \mathrm{ml} / \mathrm{sec}$.

Clinical-Cytological Grading has been previously described in detail elsewhere ${ }^{67}$. Briefly, CCG is a score based on both nasal cytology findings and comorbidities, including asthma, allergy and ASA sensitivity. For each variable, a score value was assigned: neutrophilic infiltrate was scored as 1, mast cell infiltrate was scored 1 , eosinophilic infiltrate was scored 2, eosinophilic + mast cell was scored 4; similarly, ASA sensitivity scored 1, asthma 2, allergy 2 and ASA sensitivity + asthma 3. The CCG was composed as the sum of these individual scores. A global score between 1-3 is considered low grade, 4-6 moderate and $>7$ severe, as reported in Figure $1^{67}$.

Sniffin' Sticks test was performed in all patients and TDI score was calculated according to a Position Paper on olfactory dysfunction ${ }^{22}$. The composite TDI score is the sum of each item, including olfactory functions, such as odour threshold, odour discrimination and odour identification. On the basis of the TDI score, patients can be classified as normoosmic (TDI $>30.5$ ), hypoosmic (TDI $<30.5$ and $>16.5$ ) and anosmic (TDI < 16.5). In the current study, patients were divided into 2 groups based on normosmia, such as with TDI $>30.5(\mathrm{n}=7)$, or dysosmia, such as with TDI $<30.5$ (i.e. hyposmia or anosmia; $\mathrm{n}=55)$.

\section{Statistical analysis}

Demographic and clinical characteristics were described using means with SDs for normally-distributed continuous data (i.e. age or CCG) or as absolute frequency and percentages for categorical data (i.e. male gender).

Any statistically significant difference in the mean values among patients with normal or impaired olfaction (i.e. hyposmia or anosmia) was evaluated by ANOVA followed by Bonferroni post hoc test.

Comparison of frequency distributions was made by chisquare test or Fisher's exact test in case of expected frequencies $<5$.

A receiver operating characteristic (ROC) curve analysis was performed to determine a cut-off point for CCG to identify patients with dysosmia (i.e. patients with anosmia or hyposmia). The area under the curve (AUC) is graded as follows: $\mathrm{AUC}=0.5$, no discrimination (it corresponds to a level of performance of little more than that of chance); $0.7<$ AUC $<0.8$, acceptable discrimination; $0.8<$ AUC $<0.9$, excellent discrimination; AUC $>0.9$, outstanding discrimination ${ }^{21}$. Sensitivity (i.e. the probability of the test being positive when performed on diseased patients), specificity (i.e. the probability of the test being negative when performed on healthy subjects), positive predictive value (PPV, i.e. the probability of the subject being diseased when the test result is positive, negative predictive value (NPV, i.e. the probability of not being diseased with a negative test result, Likelihood Ratio (LR) + (i.e. the ratio between sensitivity divided by 1 - specificity), LR- (i.e. the ratio between 1 - sensitivity divided by specificity), diagnostic Odds ratio (DOR, i.e. the ratio between $L R+$ and $L R-$ ) were reported.

To evaluate the role of different independent explanatory variables in association with dysosmia, multiple logistic regression analysis was performed. Variables that were considered important for the outcome a priori (i.e. age and gender) or that were statistically significant in univariate analysis $(\mathrm{P}<0.05)$ were entered into the model. The effect is expressed as adjusted odds ratio (adjOR) with 95\% confidence intervals (CIs). Statistical significance was tested using the likelihood ratio test.

Correlation between the rhinomanometry and olfactometry was evaluated with Spearman's rank-order correlation coefficient. We labelled the strength of the association as follows: for absolute values of r, 0 to 0.19 is regarded as very weak, 0.2 to 0.39 as weak, 0.40 to 0.59 as moderate, 0.6 to 0.79 as strong and 0.8 to 1 as very strong correlation ${ }^{23}$.

Statistical significance was set at $p<0.05$, and all analyses were performed using GraphPad Prism software (GraphPad Software Inc, CA, USA) and Epi-Info statistical software (Centers for Disease Control and Prevention, Atlanta, GA, USA).

\section{Results}

In CRSwNP patients, olfactory dysfunction was frequent and present in 55 patients with anosmia or hyposmia of 62 patients.

Table I reports demographic and clinical characteristics of the patients. Male gender, age, nasal polyposis severity grading and comorbidities such as allergy, asthma and/or ASA sensitivity were not different among the two groups of subjects. There was a different cytotype profile in the two 
Table I. Demographic and clinical characteristics in subjects with CRSwNP and dysosmia (such as anosmia or hyposmia) or normosmia.

\begin{tabular}{|c|c|c|c|}
\hline Variable & $\begin{array}{c}\text { Dysosmia } \\
(n=55)\end{array}$ & $\begin{array}{c}\text { Normosmia } \\
(\mathrm{n}=7)\end{array}$ & $P$ value \\
\hline Male gender & $22(40.00 \%)$ & $3(42.86 \%)$ & $1.00 \#$ \\
\hline Age [years, mean (SD)] & $50.25(14.66)$ & $47.43(15.20)$ & 0.63 \\
\hline \multicolumn{4}{|l|}{ Nasal polyposis } \\
\hline Grade 1 & $15(27.27 \%)$ & $2(28.57 \%)$ & $0.76 \#$ \\
\hline Grade 2 & $13(23.64 \%)$ & $3(42.86 \%)$ & \\
\hline Grade 3 & $20(36.36 \%)$ & $2(28.57 \%)$ & \\
\hline Grade 4 & $7(12.73 \%)$ & 0 & \\
\hline Allergy & 38 (69.09\%) & $3(42.86 \%)$ & $0.21 \#$ \\
\hline Asthma & 22 (40.00\%) & $1(14.29 \%)$ & $0.24 \#$ \\
\hline ASA sensitivity & 7 (12.73\%) & 0 & $1.00 \#$ \\
\hline Asthma + ASA sensitivity & $5(18.52 \%)$ & 0 & $0.36 \#$ \\
\hline Nasal neutrophils & $4(7.27 \%)$ & $5(71.43 \%)$ & $0.0004 \#$ \\
\hline Nasal eosinophils & $50(90.91 \%)$ & $1(14.29 \%)$ & $<0.0001 \#$ \\
\hline Mast cells & $25(45.45 \%)$ & $1(14.29 \%)$ & $0.22 \#$ \\
\hline \multicolumn{4}{|l|}{ Cytotypes } \\
\hline Neutrophils & $4(7.27 \%)$ & $5(71.43 \%)$ & $<0.0001 \#$ \\
\hline Eosinophils & $26(47.27 \%)$ & $1(14.29 \%)$ & \\
\hline Mast cells & $1(1.82 \%)$ & $1(14.29 \%)$ & \\
\hline Eosinophils + mast cells & $24(43.64 \%)$ & 0 & \\
\hline CCG [mean (SD)] & $5.84(2.20)$ & $2.86(2.48)$ & 0.0015 \\
\hline \multicolumn{4}{|l|}{ CCG score } \\
\hline $\operatorname{Low}(\leq 3)$ & $5(9.09 \%)$ & $4(57.14 \%)$ & $0.012 \#$ \\
\hline Medium (4-6) & $26(47.27 \%)$ & $2(28.57 \%)$ & \\
\hline $\operatorname{High}(\geq 7)$ & $24(43.64 \%)$ & $1(14.29 \%)$ & \\
\hline
\end{tabular}

All variables are reported as absolute frequency and percentage in parentheses unless otherwise specified. \#: Fisher exact test; ASA: Acetylsalicylic acid; CCG: clinicalcytological grading.

subgroups: compared to dysosmic patients, in normosmic subjects neutrophils were the most frequently found cells, whereas in dysosmic patients, eosinophils or eosinophils + mast cells were the most frequently found cells.

Mean CCG was significantly higher in dysosmic patients than in normosmic subjects. A low CCG score was detected in over a half of normosmic subjects, whereas there was a medium or a high CCG score in over a half of dysosmic patients.

Since the CCG score was significantly different between normosmic and dysosmic patients, we calculated the best cut-off point for CCG that was able to discriminate between patients with or without dysosmia (i.e. those with ano- or hyposmia or those with normosmia). For this purpose, a ROC curve analysis was performed (Fig. 1). The optimal cut-off value was $>4$. Performance measures for CCG as a test for discriminating between patients with dysomia and with normosmia are reported in Ta-

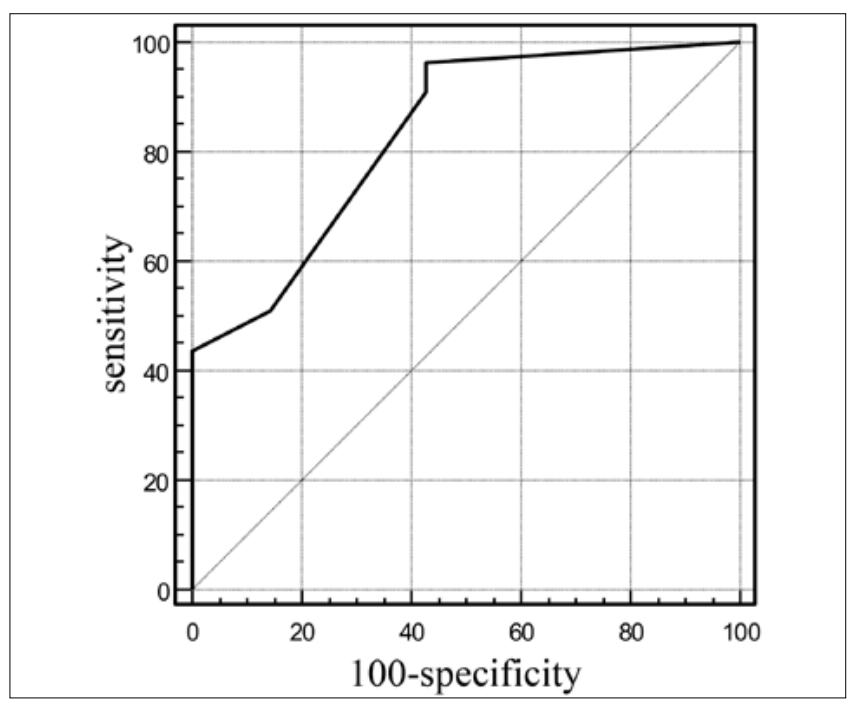

Fig. 1. Receiver operating characteristic (ROC) curve to determine the best cut-off point for CCG to identify patients with dysosmia (i.e. patients with anosmia or hyposmia).

Table II. Performance measures for CCG as test for discriminating between patients with dysosmia and subjects with normosmia (cut-off: > 4).

\begin{tabular}{lc} 
Parameter & Value \\
Sensitivity & $70.9(57.1-82.4)$ \\
Specificity & $71.4(29.3-95.5)$ \\
Positive predictive value (PPV) & 95.1 \\
Negative predictive value (NPV) & 23.8 \\
Youden index & 0.423 \\
Likelihood ratio (LR)+ & 2.48 \\
Likelihood ratio (LR)- & 0.41 \\
Diagnostic odds ratio (DOR) & 6.09 \\
\hline
\end{tabular}

ble II. The area under the ROC curve was 0.831 ( 0.715 to $0.914)$, corresponding to excellent statistical discrimination. LR+ and LR- were 2.48 and 0.41 , respectively, with a significant diagnostic odds ratio of 6.09 (1.07-34.73). This means that the risk of having dysosmia was over 6-fold higher in subjects with CCG $>4$ compared with subjects with a $\mathrm{CCG}<4$.

We also evaluated whether age or gender could have an effect on the association between CCG and dysosmia: a logistic regression model of positive CCG (>4), male gender and age as predictors of the study outcome demonstrated that positive CCG should be considered an independent prognostic factor of olfactory dysfunction in patients with nasal polyps, giving a more than 7-fold higher risk of having dysosmia in subjects with CCG $>4$ compared to subjects with a CCG $<4$ (adjOR 7.46) (Table III). Figure 2 reports the distribution of normosmia 


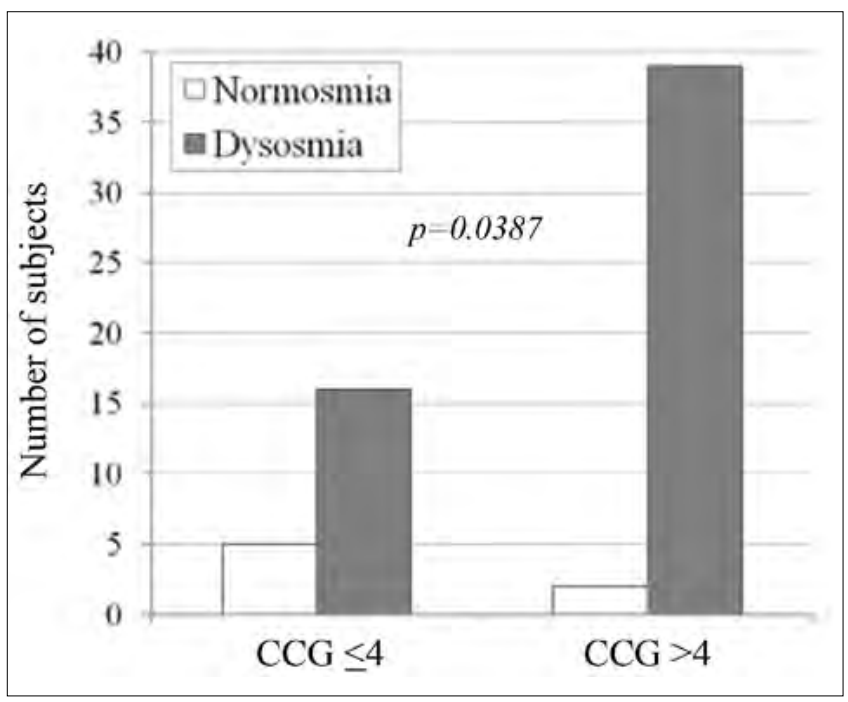

Fig. 2. Distribution of normosmia and dysosmia in patients with CCG $>4$ or $\mathrm{CCG}<4$ score.

and dysosmia in patients with a $\mathrm{CCG}>4$ or a $\mathrm{CCG}<4$. In the group with positive CCG, the proportion of dysosmic patients was significantly higher as to normosmic subjects (Fisher exact test, $\mathrm{p}=0.0387$ ).
No correlation was found between olfactometry and rhinomanometry ( $r=-0.1978, p=0.12)$ (Fig. 3A). There was a moderate and significant inverse relationship between CCG and olfactometry ( $\mathrm{r}=-0.42 ; \mathrm{p}<0.0007)$, as reported in Figure 3B.

\section{Discussion}

The current study demonstrated that olfactory dysfunction is frequent in CRSwNP patients and that there is an association between olfactory impairment and inflammation. In addition, a CCG score $>4$ is significantly associated with dysosmia. Actually, CCG could be useful in clinical practice to phenotype CRSwNP patients, identify the best treatment, and avoid under or overtreatment ${ }^{724}$. Moreover, olfactory dysfunction in patients with CRSwNP is an intriguing topic that is argument of research and clinical debate ${ }^{25-27}$.

On the basis of this background, we explored the potential factors associated with olfactory dysfunction in patients with CRSwNP in real-world experience. Notably, about $90 \%$ of our CRSwNP patients had olfactory dysfunction that was not associated with nasal obstruction, as evaluated by endoscopy grading and rhinomanometry.

Table III. Logistic regression model of positive CCG, male gender and age as predictors of the study outcome.

\begin{tabular}{lcccc} 
Outcome & Explanatory variables & Adjusted odds ratio & 95\% Cl & P value \\
Dysosmia (yes vs. no) & CCG $(>4)$ & 7.46 & $1.18-47.19$ & 0.0328 \\
& Male gender & 1.59 & $0.28-9.03$ & 0.6000 \\
& Age (yr) & 1.02 & $0.96-1.08$ & 0.4759 \\
\hline
\end{tabular}

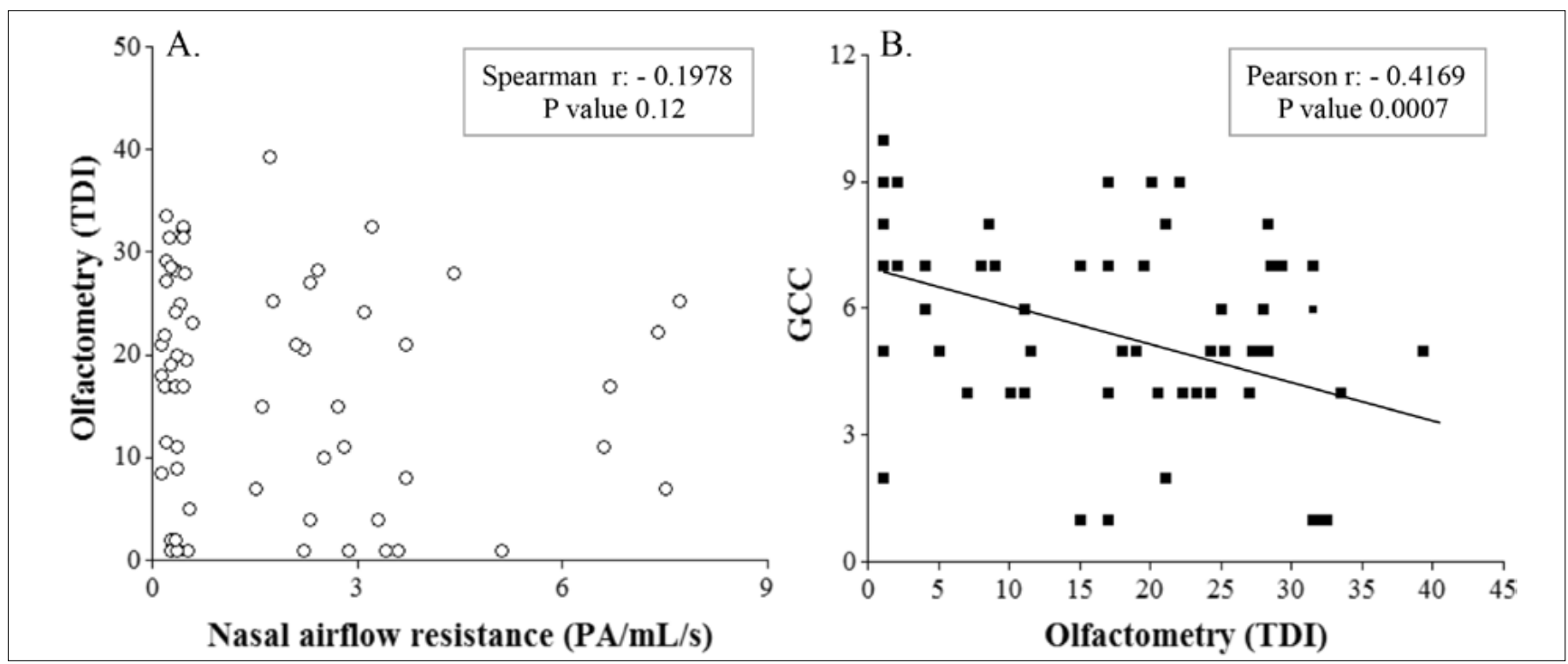

Fig. 3. Correlation between olfactometry and rhinomanometry (A) or CCG (B). 
On the contrary, olfactory impairment was associated with inflammation, mainly concerning the eosinophilic and mast cell infiltrate.

From a clinical point of view, the assessment of the CCG could also be useful to suspect olfactory impairment in patients with a score $>4$. Obviously, a diagnosis of impaired sense of smell should be based on specific olfactory testing.

However, the current study has some limitations, including the small number of patients (overall there was also a relevant imbalance between subgroups: 55 patients with dysosmia and only 7 with normosmia), the common presence of allergic rhinitis and its cross-sectional design. However, the study design was real-world to mirror daily clinical practice and newly diagnosed CRSwNP was a specific inclusion criterion. Therefore, a limited number of patients can be enrolled over a one year period. In addition, as the study was performed in a real-world setting, the percentage of normosmic patients was very low, as expected. Allergic patients were included as this comorbidity is very common and their exclusion drastically diminished the sample size. regarding the third issue, a follow-up longitudinal study is ongoing to evaluate whether CCG can predict persistent olfactory dysfunction over time after surgical treatment.

Nasal cytology has some limitations, including the limited reproducibility due to several factors, such as the area of the scaping, quantity of recovered cells, variations over time and training of the operator. Consequently, these limitations could influence the current findings and their interpretation. In conclusion, the present study underlines that olfactory dysfunction is common in CRSwNP patients and demonstrates an association between olfactory dysfunction and inflammation and is consistent with findings obtained in the model of obstructive sleep apnoea ${ }^{28}$. Moreover, CCG may be useful in the work-up of CRSwNP patients and a CCG score $>4$ could lead the clinician to suspect of olfactory impairment.

\section{Conflict of interest statement}

None declared.

\section{References}

1 Fokkens WJ, Lund VJ, Mullol J, et al. EPOS2012: European position paper on rhinosinusitis and nasal polyps 2012. A summary for otorhinolaryngologists. Rhinology 2012;50:1-12. https://doi. org/10.4193/Rhino50E2.

2 Bachert C, Zhang N, Holtappels G, et al. Presence of IL-5 protein and IgE antibodies to staphylococcal enterotoxins in nasal polyps is associated with comorbid asthma. J Allergy Clin Immunol 2010;126:962-8. https://doi.org/10.1016/j.jaci.2010.07.007.

3 Meltzer EO, Hamilos DL, Hadley JA, et al. Rhinosinusitis: de- veloping guidance for clinical trials. Rhinosinusitis initiative. J Allergy Clin Immunol 2006;118(Suppl 5):S17-61. https://doi. org/10.1016/j.jaci.2006.09.005.

4 Lund VJ, Kennedy DW. Staging for rhinosinusitis. Otolaryngol Head Neck Surg 1997; 117:S35-40.

5 Gelardi M, Russo C, Fiorella ML, et al. Inflammatory cell types in nasal polyps. Cytopathology 2010;2:201-3. https://doi. org/10.1111/j.1365-2303.2009.00671.x.

6 Gelardi M, Fiorella R, Fiorella ML, et al. Nasal-sinus polyposis: clinical-cytological grading and prognostic index of relapse. $\mathrm{J}$ Biol Regul Homeost Agents 2009; 23:181-8.

7 Gelardi M, Iannuzzi L, De Giosa M, et al. Non-surgical management of chronic rhinosinusitis with 1 nasal polyps based on clinical cytological grading: a precision medicine-based approach. Acta Otorhinolaryngol Ital 2017;37:38-45. https://doi. org/10.14639/0392-100X-1417.

8 Mullol J, Alobid I, Marino-Sanchez F, et al. Furthering the understanding of olfaction, prevalence of loss of smell and risk factors: a population-based survey (OLFACAT study). BMJ Open 2012;2:2001256. https://doi.org/10.1136/ bmjopen-2012-001256.

9 Croy I, Nordin S, Hummel T. Olfactory disorders and quality of life - an updated review. Chem Senses 2014;39:185-94. https://doi. org/10.1093/chemse/bjt072.

10 Damm M, Quante G. Impact of functional endoscopic sinus surgery on symptoms and quality of life in chronic rhinosinusitis. Laryngoscope 2002;112:310-5. https://doi.org/10.1097/00005537200202000-00020.

11 Delank KW, Stoll W. Olfactory function after functional endoscopic sinus surgery for chronic sinusitis. Rhinology 1998;36:15-9.

12 Stevenson RJ. Olfactory perception, cognition, and dysfunction in humans.Wiley Interdiscip Rev Cogn Sci 2013;4:273-84. https:// doi.org/10.1002/wcs.1224.

13 Nguyen DT, Rumeau C, Gallet P, et al. Olfactory exploration: state of the art. Eur Ann Otolaryngol Head Neck Dis 2016;133:113-8. https://doi.org/10.1016/j.anorl.2015.08.038.

14 Haxel BR, Boessert P, Weyer-Elberich V, et al. Course of olfaction after sinus surgery for chronic rhinosinusitis. Laryngoscope Investig Otolaryngol 2017;2:269-75. https://doi.org/10.1002/ lio2.109.

15 Wolfensberger M, Schnieper S. Sniffin'Sticks: a new olfactory test battery. Acta Otolaryngol 2000;120:303-6. https://doi. org/10.1080/000164800750001134.

16 Hummel T, Kobal G, Gudziol H, et al. Normative data for the "Sniffin' Sticks" including tests of odor identification, odor discrimination, and olfactory thresholds: an upgrade based on a group of more than 3,000 subjects. Eur Arch Otorhinolaryngol 2007;264:237-43. https://doi.org/10.1007/s00405-006-0173-0.

17 Hummel T, Sekinger B, Wolf S, et al. "Sniffin' Sticks": olfactory performance assessed by the combined testing of odor identification, odor discrimination and olfactory threshold. Chem Senses 1997;22:39-52. https://doi.org/10.1093/chemse/22.1.39.

18 Kobal G, Hummel T, Sekinger B, et al. "Sniffin' Sticks": screening of olfactory performance. Rhinology 1996;34:222-6.

19 Orlandi RR, Smith TL, Marple BF, et al. Update on evidencebased reviews with recommendations in adult chronic rhinosinusitis. Int Forum Allergy Rhinol 2014;4(Suppl 1):S1-15. https://doi. org/10.1002/alr.21344.

20 Gelardi M, Iannuzzi L, Quaranta N, et al. Nasal cytology: practical aspects and clinical relevance. Clin Exp Allergy 2016;46:78592. https://doi.org/10.1111/cea.12730.

21 Bousquet J, Heinzerling L, Bachert C, et al.; Global Allergy and 
Asthma European Network. Practical guide to skin prick tests in allergy to aeroallergens. Allergy 2012;67:18-24. https://doi. org/10.1111/j.1398-9995.2011.02728.x.

22 Hummel T, Whitcroft KL, Andrews P, et al. Position paper on olfactory dysfunction. Rhinology 2017;54:1-3. https://doi.org/10.4193/ Rhin16.248.

23 Hosmer DW, Lemeshow S. Applied logistic regression. $2^{\text {nd }}$ ed. New York: John Wiley \& Sons; 2000. pp. 160-4.

24 Swinscow TDV. Correlation and regression. In: Swinscow TDV, Campbell MJ, editors. Statistics at square one. $9^{\text {th }}$ ed. Southampton: BMJ Publishing Group; 1997. pp. 75-84.

25 Ottaviano G, Savietto E, Scarpa B, et al. Influence of number of drugs on olfaction in the elderly. Rhinology 2018;56:351-357. https://doi.org/10.4193/Rhin17.152.
26 Hopkins $\mathrm{C}$, Philpott $\mathrm{C}$, Crowe $\mathrm{S}$, et al. Identifying the most important outcomes for systematic reviews of interventions for rhinosinusitis in adults: working with patients, public and practitioners. Rhinology 2016;54:20-6. https://doi.org/10.4193/ Rhin 15.199.

27 Pistochini A, Rossi F, Gallo S, et al. Multiple gene expression profiling suggests epithelial dysfunction in polypoid chronic rhinosinusitis. Acta Otorhinolaryngol Ital 2019;39:169-77. https://doi. org/10.14639/0392-100X-2361.

28 Magliulo G, De Vincentiis M, Iannella G, et al. Olfactory evaluation in obstructive sleep apnoea patients. Acta Otorhinolaryngol Ital 2018;38:338-45. https://doi.org/10.14639/0392100X-1981.

Received: November 15, 2018 - Accepted: March 12, 2019

How to cite this article: Gelardi M, Piccininni K, Quaranta N, et al. Olfactory dysfunction in patients with chronic rhinosinusitis with nasal polyps is associated with clinical-cytological grading severity. Acta Otorhinolaryngol Ital 2019;39:329-335. https://doi. org/10.14639/0392-100X-2426

Address for correspondence: Giorgio Ciprandi, Allergy Clinic, Casa di Cura Villa Montallegro, via Boselli 5, 16146 Genoa, Italy. E-mail: gio.cip@libero.it

This is an open access article distributed in accordance with the Creative Commons Attribution Non Commercial (CC BY-NC 4.0) license, which permits others to distribute, remix, adapt, build upon this work non-commercially, and license their derivative works on different terms, provided the original work is properly cited, appropriate credit is given, any changes made indicated, and the use is non-commercial. See: http://creativecommons.org/licenses/by-nc/4.0/. 